\title{
A Showcase of Teamwork Enhancement through Teambuilding Activities in Vietnam
}

\author{
Thuy Thanh Thi Doan ${ }^{1}$ \\ ${ }^{1}$ Faculty of Education, Monash University, Australia \\ Correspondences: Thuy Thanh Thi Doan, Faculty of Education, Monash University, Australia. E-mail: \\ mattron2001@yahoo.com \\ Received: October 5, 2015 \\ Accepted: October 15, 2015 \\ Online Published: October 19, 2015 \\ doi:10.5430/jbar.v4n2p40 \\ URL: http://dx.doi.org/10.5430/jbar.v4n2p40
}

\begin{abstract}
Teamwork has been regarded as an important vehicle for an organization to achieve success. Many leading enterprises around the world have implemented programs to promote their staffs' teamwork spirit. In the Vietnamese context, leaders tend to focus on improving corporate government in which enhancing human resources and collaboration among employees is a need. Thus, promoting culture of teamwork to adapt to the fast changing market-driven economy in these enterprises has become a significant factor for their survival. This paper provides a showcase of the enhancement of the teamwork through a teambuilding program in Ho Chi Minh Stock Exchange (HOSE) in 2014. Two hundred and one participants divided into six teams attended the program and underwent teambuilding activities and team performances. The findings elicited from observation data showed that the program was successful in building and improving the culture of teamwork across all the six teams in light of team membership, team problem relationship, team problem solving, team leadership and organizational environment. The success of this activity made a significant contribution in enhancing intimate relationships among HOSE's employees. Based on the results, recommendations are given to improve organization's culture of teamwork through implementing teambuilding activities.
\end{abstract}

Keywords: Team, Culture of teamwork, Teambuilding, Vietnam, Public sector

\section{Introduction}

Human resource management in the modern business environment is facing challenges due to the lack of teamwork spirits among staff members. Building and improving a culture of team work play a vital role in the development of business, thus become one of the most significant goals that senior executives aim to achieve (Piasecki, 2013). That everyone shares the same thing, acts in the same way and cooperatively makes decisions will produce more efficient results than when things are done individually (LaFasto \& Larson, 2001). In order to create and improve a culture of teamwork, employee's trust, collaboration and accountability are necessary requirements (Becker, 2015). Consequently, a company with a strong culture of teamwork will generate personnel's job satisfaction and hence more effective job performance.

As one of the most effective activities to enhance culture of teamwork, teambuilding events are commonly organized in businesses. Team building programs focus on enhancing good communication and reducing conflicts among participants as team members. Moreover, the knowledge and skills of individual team members can be developed since teamwork activities require coordination and combination of capabilities in complex ways of the members (Dick, 1996). With higher levels of trust and support from other members, individuals as members of teams will interact with the others to improve company's policies and procedures. This will lead to an increase in their creativity, productivity as well as job satisfaction and commitment (Fapohunda, 2013). This paper will present a showcase of how teamwork culture was enhanced through teambuilding activities organized in Ho Chi Minh Stock Exchange (HOSE) in 2014.

\subsection{Team, culture of teamwork and the formation of a team}

Teams are formed by people who have the same belief or share the same goals and interact or influence each other to gain the teams' goals. Thus, everyone involving in any team should be considered as a team member rather than as separated individuals (Greenberg \& Baron, 1997). Teamwork includes a wide range of activities in which every individual in a team share their knowledge, skills or attitudes with other members of the team so that they could work 
together effectively and efficiently to achieve specific goals. Normally, the goals of each team have a close relation with companies' objectives or targets. Also through team work, individuals can develop their competencies, knowledge skills, which is considered a kind of in-place career development (Cianni \& Wnuck, 1997).

Every team involves in several stages of establishment and performance. According to Tuckman and Jensen (1977), the stages include forming, storming, norming and performing. In the first stage, people from different backgrounds are chosen for particular purposes to join a group or a team. In the next period, several conflicts or different points of view occur among team members when they share their opinions about missions or approaches. In addition, many challenges occur as some people tend to resist to work with unfamiliar people (Fapohunda, 2013). According to Folger and Skarlicki (1999) the reason is that any changes in organizationa sometime can be a cause to a group of employee's skepticism and resistance. Some negative employees believe that such teambuilding events cause a waste of time and they become cynical of the company. As a result, this type of employees loses their trust in the organization, decreasing their productivity and the observation of certain ethics principles during the realization of their activities. Especially, when people prefer to make decisions rather than being told what to do, they ignore collaboration if they are not trusted or empowered. However, these obstacles are overcome in the next two stages when team members become more familiar with the others in their teams. Consequently, a more attached and intimate working relationship among them has been established as they have a better understanding of others.In this norming stage, team members will learn how to ignore the differences of individuals. In the final stage, individuals in a team are more active and collaborative to achieve the ultimate goal by taking advantage of resources and allocating them effectively. Thus, it means that a team will not be considered fully effective if it does not come into the stage of performing (Tuckman \& Jensen, 1977). After going through all stages, an assessment of its effectiveness should be carried out for the benefits of training to individuals in enhancing on-the-job performance.

\subsection{Requirements of effective teams}

According to Katzenbach and Smith (1993), a variety of requirements sequentially presented below should be followed to build and implement effective teams:

(1) The number of members should not be too many.

(2) Complementary skills should be focused.

(3) The team should have truly meaningful purpose.

(4) Teams must be set up with specific goals.

(5) Approach to the team's work should be established clearly.

(6) Team members should have a sense of mutual accountability

(7) Leadership structure should be defined appropriately.

Similarly, LaFasto and Larson (2001) outlined five similar factors of effective teams, encompassing:

(1) Team membership

(2) Team relationship

(3) Team problem solving

(4) Team leadership

(5) Organizational environment.

The findings from the study conducted by LaFasto and Larson (2001) with the participation of more than 6,000 team members from different organizations showed that these important requirements exerted effects on teams' success. The factors built by Katzenbach and Smith (1993) and by LaFasto and Larson (2001) have many similarities. For example, team membership refers to a collection of individuals whose quantity and quality of team members should be carefully taken into account. Team relationship mentions the way team members interact to the others, which requires everyone to have a sense of mutual accountability, tolerance, understanding, giving and receiving feedback effectively. In other words, strength of individual team members will lead to the team advancement (Cianni \& Wnuck, 1997). Whereas team problem solving refers to set-up goals and adequate complementary skills to achieve goals, team leadership or suitable leadership structure plays a significant role in helping teams gain their aims and objectives. Finally, organizational environment also has a crucial contribution to team's success as it impacts on teamwork's approaches. It implies that structures, systems and processes should provide appropriate and useful information and resources to promote decision-making as quickly as possible. 
In light of LaFasto and Larson (2001)'s requirements for effective teams, the effectiveness in building teams throughout a specific teambuilding event organized by HOSE in 2014 will be presented and discussed.

\section{Research design, methods and data collection}

The goal of this study was to evaluate the effectiveness of the teamwork program provided by HOSE in 2014. Thus, an evaluation research based on HOSE's case study was employed as a methodological framework for this study as its core characteristic is to "improve" rather than "prove", according to Stufflebeam and Shinkfield (1985).

In terms of research approaches, a qualitative research design was employed in this study and observation method was utilized when the team building program took place. This method was especially effective when it applied for watching interactions of people in groups to understand how they communicate with the others and how they express their feelings (Kawulich, 2005). This approach provided an added privilege to the researcher in getting internal information. The researcher played a role as an independent observer. Videos and photos of the teambuilding programs were taken to support data analysis with the consent of all the participants.

\section{Findings}

\subsection{A general description of the 2014 HOSE teambuilding program}

Teambuilding is a regular event organized every two years in HOSE. The 2014 teambuilding was the third program held in Nha Trang, a coastal city in the central region of Vietnam. A total of 201 participants were divided into six teams, each of which consisted of 33-35 members. Six proactive and creative team leaders were intentionally chosen from the middle management team of HOSE. They were expected to have excellent managerial capacity and leadership, which could inspire their team members. A total of 184 Hose's employees from 14 different departments and divisions and 11 guests as representatives of State Securities Commission (SSC) invited to participate in the event were randomly selected to make up six different teams.

The program was designed with two main parts: (1) teambuilding in the daytime and (2) team performances at nighttime. One prize would be awarded for the best teambuilding activity and two prizes would be for the best team performances. To ensure the success of the team's activities, identification and preparation of each selected activity to be carried out by the teams were done one month before the event. Six team leaders worked with their members to prepare well for the team performance in Gala Dinner event as this activity required prior-preparation for the repertoire of team performances. The teams were also requested to create their teams' names, slogans and brief introductions. The purpose was for every member to closely collaborate with one another in their teams during the preparation stage. Consequently, before the team building activity took place, six teams had their own names related to the theme of the event "Treasure of Ocean". The six teams named themselves Alibaba, Neptune, Flash, Whales, Pirates, and Sea Robbers.

The teambuilding part included with a variety of physical activities revolving around the theme "Treasure of Ocean", simulating the legend of the crews looking for the treasure to own boundless power. To find out where the treasure was, the crews must overcome six challenges, namely "offshore together", "ride the waves", "beyond the reef", "conquer the ocean", "access the treasure" and finally "excavate the treasure". These activities took place for over three hours and required the attendance of all members. For each activity, the team leaders received requests from the organizers and disseminated the requirements to the team members. They then discussed various methods and decided on the most quickly and effectively one to obtain the "Treasure", which was an old piece of leather printed with the core values of HOSE: "H" for "Human orientation", "O" for "Organizational responsibility", "S" for "Sustainable development" and "E" for "Excellent services".

In the team performances section, six teams entered two contests: "HOSE's got talent" and "Just Dance". For each competition, the minimum number of each team' attendants were at least $50 \%$ of the total members. It means that teamwork spirits and cooperation were highly required in these contests. Six contents of "HOSE's got talent" comprised three pop music songs, one cabaret theater, one tai chi dance and one comedy. In "Just Dance" competition, six teams had to imitate professional dancers in six dances: "Just Dance", "Can't take my eyes of you", "What you make me beautiful", "Bang Bang", "Marcarena" and "On the Floor".

\subsection{Findings and discussions}

As explained in Section 1.2, five dynamic factors developed by LaFasto and Larson (2001) were used to evaluate the effectiveness of the 2014 HOSE teambuilding program.

As the first requirement of a effective team, it must be built up by the right members with their suitable experience, appropriate problem-solving ability, the willingness to deal with problems, their supportiveness, action orientation, 
personal styles (LaFasto \& Larson, 2001). The 2014 HOSE teambuilding event was successful in dividing appropriate quantity and quality team members. Six teams were made up from 201 participants so that 33-35 members in each team had chances to engage in all activities together and interact with each other very well. For example, for the activity "beyond the reef", each team had to move the buoy wheel to the destination fastest. This process repeated five times in the distance of $50 \mathrm{~m}$ and required attendance of 6-7 people for each time. "This activity seemed to be easy, but very difficult as it depended upon much effort from every member to keep balance when moving the wheel" - one member of team "Neptune" said. Moreover, since it was five times of repetition, smaller groups of 6-7 people had to take turn to complete this task to ensure that everyone was not exhausted and was able to continue joining in other activities. For instance, the team "Alibaba" captain divided his team into 5 smaller groups. Each group consisted of 7 members with a balance in male and female members. In each group, one most resourceful male and one thinnest female were chosen to go inside the wheel and control it. Those who had experience in keeping balance and ability to respond promptly when operating the wheel would be selected. Meanwhile, the remaining 5 members were outside the buoy, supportively pushed the wheels to move as quickly as possible to the destination. After each small team finished this activity, the other teams alternated. The rationality in dividing groups with appropriate members in each team was one of the important reasons of their successful completion of all activities. Drawing on this activity, participants could learn that selecting right people and assigning them with the right job complementary to their previous experience and professional skills would be the utmost requirement for a successful team.

The team relationship was another key factor for the success of the six teams in overcoming challenges of this training program. Whenever the captains received new missions, they transmitted the requirements to the remaining members of the team. Everybody in the teams then discussed and offered a variety of solutions. Giving and receiving feedback could promote team relationship as team members could voice their thoughts and discuss to find the best solution to solve a problem. For example, in the activity "conquer the ocean", each team was provided simple materials such as cartons, tape, scissors, wooden sticks, etc., to form one solid boat, with adequate room for two people to paddle offshore to approach the treasure. Team "Neptune", for example, was a team which owned one of the steadiest and firmest boats. The captain revealed that:

"Everyone contributed their effort in making this fantastic boat. We had two designers for the boat first. They drew the drafts within two minutes and we then discussed together and chose the simpler one as we could not make a complex boat within 20 minutes. Right after that, 15 members started making that boat. Some cut cardboard by scissors, some pasted pieces of cardboard while some fixed the sticks and cardboard so that the boat could become solid. Meanwhile, the others supported their partners by giving feedback or taking orders from those who were responsible for each stage of making boat and immediately implement requirements. This activity was done in a synchronized manner to ensure it completed in the shortest time and of the highest quality".

This activity emphasized the creativeness of every team and consequently, six teams ended up with six different boats although they were provided the same materials. Four out of the six boats were made extremely solid and waterproof. After two people of these boats rowed out offshore to get the password and returned, these boats were still intact. However, the other two remaining boats were loosely adherent thus absorbent, unstable and sunk. These teams were doomed to failure since some team members despite being highly knowledgeable were not willing to cooperate. Their team lacked enough bonding to create successful boats. Thus, by attending this activity, participants acknowledged that discussion and negotiation among team members could lead them to the best way to deal with an issue, thus resulted in the best upshot for the teams.

Team problem solving also necessarily contributed to team's success. During the preparation for the event, the groups set a target for their teams. Two teams (team "Whales" and team "Flash") aimed to win the first prize in the team building activity instead of Gala Dinner performances as they realized their limitations in staging activities. The other two (team "Pirates" and team "Neptune"), in contrast, focused on team performances in the Gala Dinner as they possessed many staging talents in their teams. The rest two teams (team "Sea Robbers" and team "Alibaba") did not target at winning any prizes. "We just tried to get all members involved in all activities and take that purpose as the success of our teams"- all of the members of team "Sea Robbers" concluded in the meeting before the event took place. Depending on the specific goals, six teams applied different skills to achieve their goals. The two teams who aimed to win the team building prizes did not invest their time and effort in-the two contents of team performance in the evening. They tried to assign the members to support each other closely in the six activities of team building to successfully accomplish these tasks at speed. The teams who targeted at the excellence in team performances, they spent money, time and effort on "HOSE's got talent" and "Just dance" activities. Take team 
"Pirates" for example. They invited two dancing teachers and staging specialists to give them formal training. Daily, they practiced very hard with the hope that they could win the team performance prizes. "We owned two of Hose's best dancers, thus there is no reason that we will not win the "Just Dance" prize" - a member of Pirates said. "We have a beautiful voice in our team. That is the reason why we will win "Hose's got talent prize" - a Neptune's team member said. In Gala Dinner, team "Pirates" with ten sexy girls performed the "Marcarena" gracefully and won the first prize of "Just Dance" convincingly. Six teams were very clear about their strengths and weekneeses and focused on their strenghs to gain the prize, which was one of characteristics of effective team problem solving. Team problem solving ability was not only the awareness of strengths and weaknesses, but also the focus on addressing the problems to meet the job's requirements based on promoting strong points. Team "Neptune" did not achieve their desirable goal even though they owned beautiful voices. The reason was that while this program highly required teamwork spirit, the team's repertoire for "Hose's got talent" did not include the attendance of a good volume of participants. "Neptune" faced to the lack of team problem solving when building up its repertoire and was not successful to win the prize from a position of strength. The lesson from this activity showed that a team could promote their strength to achieve the best results only when they applied team problem solving effectively.

Team leadership also tremendously contributed to the effectiveness of the teams. Although the leaders who were intentionally chosen from 14 departments and divisions and were all middle management staff of HOSE, their differences in management styles and levels of interest and commitment to their teams led their teams to different results. The teams run by the leaders with more managerial experiences were more likely to achieve expected results. The three teams who won the first prizes in "Team building activities", "Just Dance" and "HOSE's got talent" were all led by senior managers while the other teams were managed by junior ones. These senior managers spent a lot of time on preparation and provided their team members with adequate encouragements and support while the event was in process. They also made the right decisions in response to emergencies. For example, in the team building activities, a member of team "Whales" was injured and admitted to hospital. The leader of this team immediately decided to send a relief for his performance in Gala Dinner. This stuntman was requested to learn the acting role and rehearsed within six intensive hours. His performance was completed successfully and highly appreciated by the Board of Management. The team leader's timely decision was also given compliments. The success of the six teams illustrated that, team leaders were the survivals of teams. Without the leadership of the captain, the team members were just a discrete set of individuals. The leaders set up team's goals, drew direction, collected and inspired team members to achieve their goals. They were worth being considered significant keys to enhance the culture of teamwork.

Finally, in terms of organizational environment factor, HOSE's culture of teamwork was encouraged and promoted by the Board of Directors and Board of Management. Despite the company's financial difficulties, team building programs were organized as a regular training event. The senior executives believed that enhancing culture of teamwork has been one of priorities in the development of HOSE in which teambuilding events have become indispensable. They always followed up the activities of the team, participating enthusiastically as the other team members. In particular, in the Gala Dinner, all seven members of the Board and representatives from SSC involved in one opening dance repertoire, bringing excitement to the employees. The Chairman said "As senior executives, we are trying to support all activities that help promote HOSE's culture of teamwork. We highly appreciate and immediately reward the new ideas to build up intimate collaboration between employees. However, as an individual, when I join the team, I am just a team member. I am no longer the Chairman. I am ready to obey the orders of the captain and consider team victory is more important than personal victory". The organizational environment factor including effective management practise and systems, structure and processes particularly led the program to success through which the culture of teamwork was improved.

\section{Conclusion and recommendation}

Drawing on LaFasto and Larson (2001)'s five criteria of team membership, team relationship, team problem solving, team leadership and organizational environment, the study evaluated the 2014 teambuilding event as successful in building effective teams. The individuals from different departments and divisions became friendlier and more cooperative with the other members in their team, from which their success stemmed.

The findings of this study also reinforced the close collaboration among the participants in their teams and with other teams, which marked significant contributions to the success of this teambuilding event (Dick, 1996). The ending scene that team members hands in hands brought pieces of puzzles onto the stage to assemble them into one painting symbolized the team work spirit in HOSE's culture. This art work was only completed with the collaboration of individuals, which was also the message of this event transmitted by the program organizers. 
The success of this teambuilding event in the context of Vietnamese public sector would be a typical example for enhancing culture of teamwork through teambuilding activities. Team members when participating in these activities and working with the others in their team could develop their attitudes, skills and behaviors. The close bonding among them thus has been strongly developed, which could strengthen the culture of teamwork and promote institution's corporate culture (Sulaiman, Mahbob, \& Hassan, 2012). As in the current business world with fierce competitions, it is teams, not individuals, which drive performance for success (Piasecki, 2013), the study suggests that other enterprises should replicate the findings of this study to promote teamwork spirit among their employees.

\section{References}

Becker, E. (2015). Team Building and Group Dynamics. Talent Development, 69(4), 100-101.

Cianni, M., \& Wnuck, D. (1997). Individual Growth and Team Enhancement: Moving Toward a New Model of Career Development. Academy Of Management Executive, 11(1), 105-115. http://dx.doi.org/10.5465/AME.1997.9707100663

Dick, B. (1996). The functions of team building and how to achieve them. Paper presented at the Bridging the gap between theory, research and practice, James Cook University of North Queensland, Townsville.

Fapohunda, T. (2013). Towards Effective Team Building in the Workplace. International Journal of Education and Research, 1(4).

Folger, R., \& Skarlicki, D. (1999). Unfairness and resistance to change: hardship as mistreatment. Journal of Organizational Change Management, , 35-50. http://dx.doi.org/10.1108/09534819910255306

Greenberg, J., \& Baron, R. A. (1997). Behaviour in Organizations: Understanding and managing the human side of work. . New Jersey: Prentice Hall.

Katzenbach, J., \& Smith, D. (1993). The discipline of teams. Harvard Business Review, 71, 111-146.

Kawulich, B. (2005). Participant Observation as a Data Collection Method Forum Qualitative Sozialforschung / Forum: Qualitative Social Research, 6(2). Retrieved from http://www.qualitative-research.net/index.php/fqs/article/view/466/996\#gcit

LaFasto, F., \& Larson, C. (2001). When Teams Work Best. Sage Publications.

Piasecki, B. (2013). Why teams matter more than ever. Public Management (00333611), 95(10), 12-15.

Stufflebeam, D. L., \& Shinkfield, A. J. (1985). Systematic Evaluation: A Self-Instructional Guide to Theory and Practice: Kluwer-Nijhoff Pub.

Sulaiman, W. I. W., Mahbob, M. H., \& Hassan, B. R. A. (2012). An Analysis on the Effectiveness of Team Building: The Impact on Human Resources. Asian Social Science, 8(5). http://dx.doi.org/10.5539/ass.v8n5p29

Tuckman, B., \& Jensen, N. (1977). Stages of small group development revisited'. Group and Organisational Studies, 2, 419-427. http://dx.doi.org/10.1177/105960117700200404 